\section{ANOTHER LOOK AT LAPAROSCOPIC LASER CHOLECYSTECTOMY}

\section{COMMENTS}

Two recent landmark publications $(1,2)$ have, with considerable publicity (Newsweek, February 12, 1990, p. 58; New York Times, Tuesday, August 14, 1990, p. 85), heralded the development of a new era in intraabdominal surgery.

The publication by Dubois (1) simply describes laparoscopic cholecystectomy techniques and early results after operations on 36 patients. A prior publication had appeared in the French surgical literature (3). Concurrently, this procedure was being developed by Reddick and Olsen in the United States, who published a series describing 25 patients undergoing laparoscopic cholecystectomy and compared these patients with 25 patients undergoing open cholecystectomy (2). Both Dubois' and Reddick's patients were cured of their biliary tract disease with minimally invasive procedures. The procedure may have been initially performed in pigs, in 1986, by Cuschieri in Scotland, and in humans, in 1987, in Lyons, France, by a surgeon named Mouret (4). In addition to Dubois and Reddick, Perissat and colleagues in Bordeaux, France, developed the technique early (5).

Expansion of laparoscopic surgical techniques, skill and instrumentation is occurring safely and rapidly, with the opportunity to provide patients with comparable surgical care with less morbidity and disability (6).

Enthusiasm for converting the performance of operative procedures traditionally performed through laparotomy incisions or standard hernia incisions to procedures performed through laparoscopes is caused by three important factors: wound infection, hernia formation and the disability produced by standard incisions. The incidence of wound infection associated with cholecystectomy is approximately $7 \%$ (7). Ventral hernia formation is highly related to wound infection and occurs in approximately $8 \%$ of patients with abdominal incisions (8). The employment disability after operations associated with a standard cholecystectomy can be anticipated to be approximately 28 days $(2,9)$. On the other hand, wound infection and ventral hernia rates associated with laparoscopic procedures are approximately $0.1 \%$ each $(10)$, and the employment disability associated with cholecystectomy is reduced from approximately 30 days to 6 days when the procedure is performed laparoscopically (2).

It appears unlikely that a randomized controlled trial evaluating the risks and benefits of laparoscopic cholecystectomy compared with other forms of managing calculous biliary tract disease, including open cholecystectomy, will be performed. Treatment programs that do not remove the gallbladder are currently associated with the redevelopment of the disease and the absence of a permanent cure. Open cholecystectomy, even when performed as a mini-laparotomy (2), has six times the disability period after operations associated with laparoscopic cholecystectomy that is not likely to be balanced by increased operative complications associated with laparoscopic cholecystectomy.
The two preliminary reports including 61 patients treated by laparoscopic cholecystectomy described no complications $(1,2)$. In St. Louis, 247 patients underwent laparoscopic cholecystectomy in two community hospitals and a university hospital over a 12 mo period. Two patients had bleeding after the operations that required transfusions but not more operations. One patient had a perforation of the duodenum that required exploration and closure, and jaundice developed in one patient after the operation, which was demonstrated by cholangiography to be unrelated to common duct stones or injury and disappeared spontaneously. These procedures were performed by six different surgeons. Aborting laparoscopic removal of the gallbladder in favor of standard open cholecystectomy occurred in approximately $10 \%$ of the patients undergoing laparoscopic cholecystectomy. One death from a stroke after the operation occurred in a 76-yr-old patient converted to standard open cholecystectomy because of gangrenous cholecystitis.

Laparoscopic cholecystectomy and other laparoscopic procedures are undoubtedly going to be used more often; however, numerous questions remain to be answered. The first questions raised are related to training and credentialing. Several authoritative groups, including the American College of Surgeons and the Society for Surgery of the Alimentary Tract, have issued explicit directives identifying the criterion for issuing credentials to perform laparoscopic cholecystectomy (5). Basically, a trained general surgeon certified to perform open cholecystectomy who has laparoscopic experience or training is qualified to be credentialed by hospital credentials committees. How intense the laparoscopic experience needs to be is indeterminant. Alternatives vary from a 1 to 2 day continuing medical education-type course to performance of a certain number of laparoscopic procedures with an experienced laparoscopist (usually a gynecologist). Obviously, laparoscopic procedures will need to become part of the training of general surgery residents.

Other important questions relate to the operative procedure itself and its role in managing calculous biliary tract disease. The performance of cholangiography during open cholecystectomy has been a vigorously debated issue. Some surgeons believe cholangiograms should be performed routinely during open cholecystectomy, but others feel the study should be done selectively (11). The same debate will likely develop in relationship to laparoscopic cholecystectomy.

Routine cholangiography at the time of laparoscopic cholecystectomy will help ensure the safe performance of the procedure, avoid common duct injuries and document choledocholithiasis and other common duct pathological conditions. Cholangiography will increase the length of time and cost of laparoscopic cholecystectomy.

An important consideration enabling the biliary tract surgeon to identify the presence of choledocholithiasis during open cholecystectomy is the size of the common duct and the palpation of the common duct to feel stones. These findings are not directly available to the surgeon 
during laparoscopic cholecystectomy, and more frequent use of cholangiograms may compensate for the loss. In our initial experience with cholangiography, we successfully performed technically satisfactory cystic duct cholangiograms during laparoscopic cholecystectomy in $93 \%$ of the patients, disclosing pathological conditions in $8 \%$ (12).

Dubois et al. (1) mentioned that cholecystograms could be performed during laparoscopic cholecystectomy, whereas Reddick and Olsen described cystic duct cholangiography and believed it would be possible to perform it in $75 \%$ of the patients (2).

The delineation of common duct stones before or during an operation will present a dilemma concerning the patient's management. Should the patient undergo endoscopic stone extraction and laparoscopic cholecystectomy or open cholecystectomy and standard common duct exploration? This question has been difficult to answer in previous studies that discussed the need to eliminate the morbidity of common duct exploration associated with open cholecystectomy. It appears to be the majority opinion that a patient with obstructive jaundice from gallstones, with the gallbladder intact, is appropriately treated by open cholecystectomy and standard common duct exploration (13).

A randomized prospective trial comparing laparoscopic cholecystectomy followed or preceded by endoscopic retrograde cholangiopancreatography and common duct stone extraction compared with standard open cholecystectomy and common duct exploration will determine the success rates and complication rates associated with each approach. However, the latter approach will still have the characteristics of the disability associated with the laparotomy incision.

Lastly, a red flag of caution needs to be raised regarding laparoscopic procedures using $\mathrm{CO}_{2}$ insufflation. In gynecological laparoscopy procedures that are brief and involve healthy, young patients, $\mathrm{CO}_{2}$ absorption is rarely a problem. $\mathrm{CO}_{2}$ is a highly diffusible gas rapidly absorbed by the peritoneum (14). However, very little information is available concerning the effects of intraabdominal $\mathrm{CO}_{2}$ insufflation, under pressure, for the 1 to $2 \mathrm{hr}$ required to perform laparoscopic cholecystectomy. Preliminary information suggests that elderly patients with chronic cardiopulmonary disease develop severe hypercarbia and acidosis during laparoscopic cholecystectomy despite hyperventilation (14). Continued study of the anesthetic problems associated with laparoscopic cholecystectomy is indicated.

The development of this technological advance must assuredly be used only when indicated. Surgeons must restrict the use of laparoscopic cholecystectomy to patients with symptomatic biliary tract disease who otherwise would need open cholecystectomy.

DONALD L. KAMINSKI, M.D.

Director, General Surgery

Department of Surgery

St. Louis University Medical Center

School of Medicine

St. Louis, Missouri 63103

\section{REFERENCES}

1. Dubois F, Icard P, Berthelot G, Levard H. Celioscopic cholecystectomy, preliminary report of 36 cases. Ann Surg 1990;21 1:60-62

2. Reddick EJ, Olsen DO. Laparoscopic laser cholecystecomy: a comparison with mini-lap cholecystectomy. Surg Endosc 1989;3: 131-133.

3. Dubois F, Berthelot G, Levard H. Cholecystectomy par coelioscopie. Presse Med 1989;18:980-983.

4. Tompkins RK. Laparoscopic cholecystectomy: threat or opportunity? Arch Surg 1990;125:1245.

5. Perissat J, Collet D, Belliard R. Gallstones: laparoscopic treatment-cholecystectomy, cholecystostomy and lithotripsy. Surg Endosc 1990;4:1-5.

6. Sackier JM, Berci G. Diagnostic and interventional laparoscopy for the general surgeon. Contemp Surg 1990;37:15-26.

7. Incidence and cost of hospital-acquired infection. In: Altemeier WA, Burke JF, Pruitt BA, Sandusky WR, eds. Manual on control of infection in surgical patients. Philadelphia: JB Lippincott Co., 1984:8-17.

8. Bucknall TE, Cox PJ, Ellis H. Burst abdomen and incisional hernia: a prospective study of 1129 major laparotomies. BMJ 1982;284:931-933.

9. Fitzpatrick G, Neutra R, Gilbert JP. Cost effectiveness of cholecystectomy for silent gallstones. In: Bunker JP, Barnes BA, Mosteller F, eds. Costs, risks and benefits of surgery. New York: Oxford University Press, 1977:246.

10. Ohlgisser M, Sorokin Y, Heifetz M. Gynecologic laparoscopy: a review article. Obstet Gynecol Surv 1985;40:385-396.

11. Yip A, Lam $\mathrm{KH}$. An evaluation of routine operative cholangiography. Aust N Z J Surg 1988;58:391-395.

12. Blatner M, Wittgen $\mathrm{CM}$, Andrus $\mathrm{CH}$, Kaminski DL. Cystic duct cholangiography during laparoscopic cholecystectomy [in press].

13. Hansell DT, Miller MA, Murray WR, Gray GR, Gillespie G. Endoscopic sphincterotomy for bile duct stones in patients with intact gallbladders. Br J Surg 1989;76:856-858.

14. Montalva M, Biman-Das F. Carbon dioxide homeostasis during laparoscopy. South Med J 1976;69:602-605.

15. Wittgen CM, Andrus CH, Baudendistel LJ, Dahms TE, Kaminski DL. Analysis of hemodynamic and ventilatory parameters during laparoscopic cholecystectomy [in press].

\section{BROWN PIGMENT GALLSTONES: THE ROLE OF BACTERIAL HYDROLASES AND ANOTHER MISSED OPPORTUNITY}

Akiyoshi $T$, Nakayama $F$. Bile acid composition in brown pigment stones. Dig Dis Sci 1990;35:27-32.

\section{ABSTRACT}

The bile acids in brown pigment stones and gallbladder bile were fractionated into free acids, gly. cine and taurine conjugates, and sulfates, using diethylamino-hydroxypropyl-Sephadex LH-20 (DEAP. LH-20) column chromatography, and were quantitated by gas chromatography. Twenty-eight cases of brown pigment stones were studied and divided into two groups: those with and those without bacteria possessing bile acid-deconjugating activity. In the former, free bile acid amounted to $62 \pm 34 \%$ of the total bile acid, while in the latter, only $0.1 \%$ of total bile acid was free bile acid. The fraction of total bile acid made up of free bile acids was found to be consistently higher in brown pigment stones than in the corresponding bile, irrespective of the presence or absence of biliary infection. Free bile acid is present in negligible amounts in normal bile. Total bile acid concentration in the bile of patients with brown pigment stones was significantly less than that of controls $(13 \mathrm{vs.} 50 \mathrm{mg} / \mathrm{ml}$ ). Biliary infection is almost always present in cases with brown pigment stones. These findings suggest that 